\title{
Dónde estaba hace dos años el 7 de setiembre [1860]
}

\author{
Alexandre Dumas \\ Edición y notas : Claude Schopp \\ Textos traducidos del francés por Àngels Santa \\ y M. Carme Figuerola
}

El 2 de setiembre de 1860, estaba anclado en la bahía de Nápoles.

El rey Francisco II abrió las ventanas de su terraza, examinó durante algún tiempo con unos prismáticos la flota inglesa, francesa e italiana.

Luego, tras haber detenido su mirada sobre esos colosos del mar, hizo la gracia a mi humilde goleta de honorarla con un vistazo.

Un espectáculo bastante extraño le conmocionó entonces. Vio el puente de mi goleta cubierto de sastres que confeccionaban camisas rojas.

Ello llevó al colmo la cólera del rey Francisco II contra mí.

Hizo llamar al señor Brenier, nuestro embajador', y le dijo: "El señor Dumas impidió al general Scotti socorrer a mis soldados en la Basilicate, el señor Dumas hizo la revolución de Salerno, el señor Dumas se encuentra en el puerto de Nápoles desde donde lanza proclamas a la ciudad, distribuye armas, da camisas rojas. Pido que se fuerce al señor Dumas a abandonar la rada".

— ¡Muy bien! Majestad, respondió el señor Brenier inclinándose. Los deseos de su majestad son órdenes para mí.

Debido al azar, a la misma hora, escribía esta carta a Garibaldi:

“¡En nombre del cielo, amigo mío, ni un solo disparo más! Es inútil, Nápoles os pertenece.

\footnotetext{
${ }^{1}$ Alexandre Anatole François Henri, barón Brenier de la Renaudière (París, 22 de agosto de 1807La Lucassière-Vouvray, 27 de marzo de 1865), Ministro de Asuntos Exteriores desde el 24 de enero al 10 de abril de 1851, fue enviado a Nápoles en junio de 1859 como enviado extraordinario y ministro plenipotenciario. Fue nombrado senador el 24 de mayo de 1861. El 26 de junio, en la calle de Toledo, fue víctima de un atentado atribuido a los anti-reformistas; había recibido en la cabeza unos golpes dados con la ayuda de un bastón emplomado que lo dejaron sin conocimiento, ver Le Nord, 30 de junio de 1860.
} 
Venid rápidamente a Salerno, y, de allí, haced saber a L. R[omano ${ }^{2}$ que estáis allí. O irá a buscaros a Salerno, con una parte de los ministros, o bien os esperará en la estación de trenes.

Venid sin perder un minuto. No necesitáis ningún ejército: vuestro nombre vale todo un ejército.

Si no quisiera dejaros el placer de la sorpresa, podría enviaros una copia del discurso de será pronunciado a vuestra llegada.

¡Cuidaros y amadme!

Alex Dumas

2 de setiembre de 1860 "

Fue el capitán Orlandini del Feruccio $^{3}$ el encargado de esta carta y hacia las tres de la tarde desapareció llevándosela entre Capri y el cabo Campanella.

A las seis y media de la tarde estábamos terminando de cenar, cuando una barca armada como para la guerra acostó la Emma.

El oficial que la mandaba pidió hablar con el capitán Beaugrand ${ }^{4}$.

El capitán Beaugrand había almorzado a bordo del Protis. Su almuerzo se había convertido en cena y no habíamos vuelto a verle.

En ausencia del capitán, el oficial pidió hablar con el segundo.

El segundo estaba en Marseille.

El oficial pareció incomodado.

Me acerqué a él.

- Señor, le dije, en ausencia del capitán y del segundo, decidme lo que os trae por aquí. Soy a la vez el armador y el propietario.

- Tengo la orden, respondió el oficial con extrema educación, de dirigirme solo a un miembro del equipaje.

Llamé al piloto.

\footnotetext{
${ }^{2}$ Liborio Romano (Patù, provincia de Lecce, 1798 - Patù, 17 de julio de 1867). "El hombre que, en este momento, ocupa el puesto principal del ministerio constitucional de Nápoles es un hombre instruido, un ciudadano integro, una de las luces de la abogacía napolitana, en fin el hombre recomendable en el que hoy el país depositó toda su confianza".

${ }^{3}$ Orlandini. Oficial de marina de Garibaldi, que Dumas conoció siendo niño cuando vivía en Florencia, via Rondinelli, un alojamiento que pertenecía a su tía.

${ }^{4}$ En La isla rebelde, É. Lockroy que lo llama con el nombre transparente de Schoengross, lo describe así: "El capitán era gordo, bajo, color pan de jengibre, y de todas formas pesado. Su error más grande era tener pretensiones literarias" (p. 8). Más lejos, (p. 11), el capitán evoca su pasado: "Era conductor a bordo de los transatlánticos [...] Empleé mi tiempo libre en estudiar y, mal que bien, aprobé mis exámenes".
} 
- Vamos, Podimatas 5 , amigo mío, le dije, venid. Y escuchad atentamente lo que tiene que deciros este señor.

Me alejé y me senté de nuevo a la mesa.

El oficial napolitano habló cinco minutos con Podimatas y regresó a su barca que se alejó rápidamente.

- Y bien Podimatas, tenemos que dejar la rada de Nápoles, ¿verdad?

- Precisamente.

- Y ¿Cuándo?

— Inmediatamente.

— ¡Oh! ¡oh! Inmediatamente...Es demasiado pronto, amigo mío. No podemos dejar a nuestro capitán: se preocuparía por nosotros.

- La orden es precisa.

— ¿Qué pueden hacer de peor contra nosotros, Podimatas?

- Dispararnos.

- ¿Eso es todo? No es demasiado aterrador: tiran tan mal. Os acordáis de Milazo ¡diablos!

El capitán Beaugrand regresó a las diez. A las diez y cinco levantamos el ancla, dejando Nápoles en la mayor agitación.

Partimos hacia Castellamare con un tiempo asombrosamente en calma. A las dos ni siquiera habíamos hecho una milla. La calma duró toda la noche. A día siguiente hacia el mediodía llegamos a Castellamare.

A medida que nos acercábamos una cierta agitación se manifestaba en la plataforma del fuerte.

Era la Emma quien causaba esa agitación.

Unas veinte barcas se pusieron en movimiento y remaron hacia nosotros.

Pero en medio de todas estas barcas apareció una barca militar.

La barca nos acostó. El oficial pidió hablar con el capitán.

El capitán se levantó.

- Capitán, dijo el oficial napolitano, en un francés bastante bueno. Le está prohibido al navío la Emma permanecer en las costas del reino de Nápoles.

- Señor, pregunté al oficial, ¿puede decirme hasta dónde se extienden en este momento las costas del reino de Nápoles?

El oficial se mordió los labios.

\footnotetext{
${ }^{5}$ Apostolos /Apostolos Podimatas (nacido en la isla de Milo, 1833 - 2 de enero de 1893). Grumete en 1841 a bordo del Inflexible, a las órdenes del contralmirante de La Susse, cuyo padre era piloto. "Lo encontré en Trébizonde, a bordo del Sully [Dumas transbordó a bordo del navío el 15 de febrero de 1859], cuyo hermano era piloto. El capitán Daguerre me lo recomendó. Me lo lleve a Syra; il vigiló la ejecución de mi tratado con el constructor, embarcó a borde de un yate y llegó a Marseille". Le Monte-Cristo, "Charla", n 19, 25 de agosto de 1859, p. 291.
} 
— Ya lo ha oído, dijo al capitán Beaugrand.

— Sí, señor, respondió el capitán, pero me es imposible partir en este momento.

- ¿Por qué?

- Creyendo que iba a quedarme en Castellamare, deposité los papeles del barco en casa del cónsul.

- Vaya a buscarlos ahora mismo.

Nuestro capitán subió al bote y mandó que le condujeran a tierra.

El comandante del fuerte tenía mala suerte: el secretario del cónsul había puesto los papeles de la Emma en un cajón cerrado con llave, había guardado la llave en su bolsillo y se había ido no se sabía dónde.

Era, pues, imposible partir.

Dos barcas, con veinte hombres cada una a bordo y armados para la guerra, estacionaron a ambos lados de la Emma.

Lo que no impidió a Castellamare que había reconocido al precursor de Garibaldi de iluminar con toda su luz. Esta iluminación aterrorizó al comandante de la plaza, quien a las tres de la madrugada nos envió la siguiente misiva:

Castellamare 3 de setiembre a las 3 de la madrugada

Comandancia superior del Departamento marítimo

El comandante de la goleta Emma levantará velas inmediatamente y remará a lo largo; y mañana por la mañana el capitán solo irá a tierra a buscar los papeles — recibirá la solicitud y partirá.

Pero a pesar de la vigilancia establecida había podido enviar dos mensajeros, uno a Nápoles, el otro a Avellino. A las diez de la mañana el capitán regresó con los papeles y partimos.

Durante todo el día y toda la noche siguiente el tiempo estuvo en calma; a duras penas franqueamos el golfo de Salerno.

El cinco, a mediodía estábamos frente al pueblo de Picciota, parados esperando un barco pesquero a quien queríamos preguntar lo que estaba haciendo Garibaldi.

El patrón nos dijo que las últimas noticias anunciaban un desembarco en Sapri y la llegada de Garibaldi a Cozenza.

Mientras estábamos conversando con los hombres del barco, fuimos vistos y reconocidos desde el pueblo de Picciottta. Dos o tres barcas cargadas de tal forma que peligraban naufragar se dirigieron hacia nosotros.

Todos los hombres que iban en ellas estaban ávidos de noticias. Les dimos las más frescas. Les dijimos que en Nápoles esperaban a Garibaldi y que sólo tenía que presentarse allí para ser recibido con entusiasmo. 
Aún no se había visto nada en la costa, pero cuando la valerosa gente supo cómo estaban las cosas, hubo únicamente un grito unánime: “iViva Italia unida!"

Pensé entonces que había llegado el momento de colocar las camisas rojas que tenía a bordo y que habían llamado la atención de su Majestad Federico II.

Nuestros hombres que no esperaban parecida generosidad pasaron del entusiasmo al frenesí.

Viendo lo que sucedía en el mar y sin entender nada del cambio de vestimenta de sus compañeros, dos otras barcas no menos cargadas que las primeras se despegaron del borde y avanzaron hacia nosotros remando con fuerza.

Los recién llegados recibieron su contingente de camisas rojas y unieron sus hurras a los de sus compañeros.

Contamos. Éramos alrededor de cincuenta: un número suficiente para que se revelase todo el Cilento.

Muratori ${ }^{6}$ tomó el mando de estos cincuenta voluntarios, a los que se constituyó una caja militar de mil francos; cogió una carabina, un revólver, montó en la chalupa citándome en Nápoles y se dirigió hacia tierra en donde abordó.

Un cuarto de hora después él y sus hombres habían desaparecido en la montaña.

Durante este tiempo una pequeña brisa del noroeste se había levantado y nos empujaba hacia Messine.

Pusimos todas las velas al viento.

Llegamos allí al día siguiente hacia las 6 de la tarde.

Esperamos, llenos de ansiedad.

Transcurrió la jornada del 7.

La pasé casi toda entera con nuestro cónsul el señor Boulard7 , que no podía creer todo lo que yo le contaba.

\footnotetext{
${ }^{6}$ Crstoforo Muratori. Químico patriota que, después de tres años en prisión, se exilió a París, dónde abrió en la calle Laffitte, asociado con Francesco Crispi, un banco. Proscrito en Francia, después del atentado de Orsini, se refugió en Alger, y no regresó a Nápoles hasta después de la amnistía concedida por el rey. Se había convertido en el confidente de Liborio Romano, ver cartas, L'Indipendente, 31 de diciembre de 1860.

${ }^{7}$ Hugues Boulard. Abogado de la abogacía de París, que entró en 1839 en los servicios diplomáticos; fue vice-consul de Francia en Messine de 1849 a 1867. Luego fue cónsul en Ancône (1868-1870). Su correspondencia con el Ministro de Asuntos exteriores, Thouvenel, fue analizada en Ferdinand Boyer, "Garibaldi et les Siciliens d'après les consuls de France à Palerme et à Messine (mai-août
} 
Al día siguiente, 8 , a las 5 de la mañana oí que me llamaban a través de la cubierta.

Pregunté que querían de mí.

"Garibaldi entró ayer, día 7, al mediodía en Nápoles, me respondieron, en medio de la alegría universal y sin disparar un solo tiro".

Lancé un grito de gozo y me precipité al puente.

¡No sé si en toda mi vida había experimentado una emoción tan viva y tan completamente desprovista de ningún accesorio doloroso!

$$
\text { * }
$$

¡Ay! Hoy al despertarnos - el mismo día de este gran aniversariooímos este grito exhalado por todos los periódicos ingleses, franceses italianos: "¡Majestad, amnistía!"

Es un grito aún más dulce, Majestad, en la boca del Rey que lo concede que en los oídos de aquel a quien se le concede.

Alex Dumas

Autógrafo: Les Autographes, Thierry Bodin, 86, printemps 199, 95 - Catalogue, p. 9 Dónde estaba - Hace dos años el 7 de setiembre/ El 3 de setiembre 1860.-Lettres et manuscrits autographes. Collection du Dr. C. Venta del jueves 21 de febrero 2013, salle Favart $n^{\circ} 60$ (expert: Thierry Bodin).

Publicación en italiano: "Ove mi trovato or son due anni il 7 settembre", L'Indipendente, anno II, nº6, 9 de setiembre 1862.

1860)", estratto dalla Rassegna Storica del Risorgimento, anno XXXIX, Fascicolo IV, OttobreDicembre 1952, Roma, La Librería dello Stato, 1852, p. 441-449. 